\title{
REKONSTRUKSI KONSTITUSI DALAM REGIONAL REPRESENTATIVE DEWAN PERWAKILAN DAERAH TERHADAP FUNGSI LEGISLATIF
}

\author{
Hezron Sabar Rotua Tinambunan dan Dicky Eko Prasetio \\ Fakultas Ilmu Sosial dan Hukum, Universitas Negeri Surabaya \\ J1. Ketintang Surabaya, Jawa Timur 60264 \\ hezrontinambunan@unesa.ac.id
}

\begin{abstract}
The Regional Representative Council or DPD is a legislative body established in 1998 reform turmoil whose juridical existence related to the DPD and its authority is based on Article 22D of the 1945 Indonesian Constitution. In the regelende functie, the DPD's role is actually as a regional representative to balance the role of the House of Representatives as political. The purpose of this study is to review and reanalyze how the DPD should exist by using a normative juridical method through a statute approach and analytical approach, that DPD membership must be an individual candidate free from party positions and functionaries political. This is to reinforce and optimize the role of regional representatives so that the nomination, appointment and policy formulation processes are individuals who are truly concerned about the problems, dynamics, and interests of the region they represent.
\end{abstract}

Keywords: DPD; Regional Representation; Reconstruction of Constitution

\begin{abstract}
Abstrak
Dewan Perwakilan Daerah atau DPD merupakan lembaga legislatif yang lahir dari gejolak reformasi 1998 yang keberadaan yuridis terkait DPD dan kewenangannya didasarkan Pasal 22D UUD NRI 1945. Dalam regelende functie maka sejatinya peran DPD sebagai perwakkilan daerah untuk mengimbangi adanya peran Dewan Perwakilan Rakyat sebagai political. Tujuan dari penelitian ini adalah untuk meninjau dan menganalisis kembali bagaimana seharusnya keberadaan DPD dengan menggunakan metode yuridis normatif melalui pendekatan perundangundangan (statute approach) dan pendekatan analitis (analytical approch), bahwa keanggotaan DPD haruslah merupakan calon perseorangan yang terbebas dari jabatan dan fungsionaris partai politik. Hal ini untuk mempertegas serta mengoptimalkan peran regional representative supaya dari proses pencalonan, pengangkatan, dan perumusan kebijakan merupakan perorangan yang benar-benar concern terhadap permasalahan, dinamika, dan kepentingan daerah yang diwakilinya.
\end{abstract}

Kata Kunci: DPD; Regional Representative; Rekonstruksi Konstitusi

\section{A. Pendahuluan}

Indonesia sebagai negara yang menganut paham constitutional democracy sebagaimana yang tercantum dalam UUD NRI 1945 mengindikasikan bahwa selain menganut konsep kedaulatan rakyat juga menganut konsep adanya pembatasan kekuasaan negara sesuai dengan konstitusi (Jimly Asshidiqie, 2006b). Sebagai pengatur kehidupan berbangsa dan bernegara, konstitusi Indonesia yaitu UUD NRI 1945 membagi kekuasaan negara menjadi 3 wilayah yakni: legislatif, eksekutif, dan yudisial. Salah satu kekuasaan negara tersebut adalah kekuasaan legislatif 
memiliki fungsi utama sebagai regelende functie atau fungsi pengaturan (Jimly Asshidiqie, 2006c). Di mana dalam regelende functie tersebut terdapat juga mekanisme di mana peraturan-peraturan tersebut dibuat oleh wakil-wakil rakyat yang merupakan pilihan rakyat sendiri. Di Indonesia, wakil rakyat tersebut terdiri dari Dewan Perwakilan Rakyat (yang selanjutnya disebut DPR) dan Dewan Perwakilan Daerah (yang selanjutnya disebut DPD) sebagai wujud dianutnya sistem bikameral di Indonesia (Prayudi, 2006).

Dewan Perwakilan Daerah yang selanjutnya disingkat dengan DPD merupakan lembaga wakil rakyat dari daerah yang lahir sebagai bagian dari tuntutan reformasi 1998 sejatinya bertujuan untuk mengembalikan marwah kedaulatan rakyat di daerah untuk tidak selalu dimonopoli oleh perwakilan rakyat melalui mekanisme politis (Miki Pirmansyah, 2014). Berangkat dari realitas dalam Pasal 22D UUD NRI 1945 terkait DPD dan kewenangannya dalam regelende functie maka sejatinya peran DPD sebagai regional representative untuk mengimbangi adanya peran Dewan Perwakilan Rakyat sebagai political representative dapat dikatakan masih belum optimal dan masih secara parsial (Prayudi, 2006). Dalam hal ini kedudukan DPD masih dianggap sebagai co-legislator bagi DPR, sehingga baik dalam penyusunan suatu Rancangan Undang-Undang (yang selanjutnya disebut RUU) menjadi UU maupun dalam hal penyaluran aspirasi masyarakat, fungsi DPD belum dijalankan secara maksimal.

Desain ketatanegaraan Indonesia secara umum dapat dijelaskan melalui teori organ yang membagi organ ketatanegaraan Indonesia menjadi dua yaitu state main organ (lembaga utama negara) dan state auxiliary organ (lembaga negara bantu/penunjang) (Ahmad Basarah, 2014). Dalam teori organ, kedudukan DPD adalah sebagai state main organ yang memiliki fungsi untuk mewakili aspirasi masyarakat daerah serta ikut membahas RUU yang berkaitan dengan kepentingan daerah seperti pembentukan, pemekaran, dan penggabungan daerah, serta kepentingan daerah lainnya seperti yang tercantum dalam
Pasal 22D UUD NRI 1945. Dalam hal ini, kedudukan antara DPD dan DPR dalam teori organ adalah setara dan sederajat, hanya dalam beberapa fungsi tertentu yang berbeda karena DPR sebagai political representative dan DPD sebagai regional representative. Namun, menjadi timpang karena kedudukan dan fungsi DPR seolah-oleh "determinan" terhadap DPD, apalagi dalam konstitusi DPD tidak memiliki fungsi untuk membuat undang-undang (rulemaking).

Dilihat dari perspektif perbandingan dengan negara lain, kedudukan regional representative seperti senate di Amerika Serikat, House of Lords di Inggris, maupun Eeerste Kamer di Belanda memiliki kedudukan yang kuat dan memiliki fungsi yang sama dengan political representative untuk membentuk undang-undang, meski dengan proporsi yang berbeda sehingga sering disebut sebagai second chambers (James R. Rodgers, n.d.). Peran second chambers tersebut memiliki kedudukan fungsi yang sama dalam penyusunan UU, sehingga dalam lembaga legislatif terdapat mekanisme legislative control yang dapat mengoptimalkan fungsi aspirasi dan penyusunan UU (Mariana Llanos dan Detlef Nolte, 2003). Fungsi aspirasi dan penyusunan UU tersebut dapat optimal apabila ada keseimbangan lembaga perwakilan rakyat antara regional dan political representation untuk melaksanakan kewenangan masing-masing scara bersamaan. Dalam hal ini, peran kedua kamar dalam suatu fungsi legislatif untuk membahas RUU maupun menyusun UU dapat lebih optimal dengan adanya kombinasi dari lembaga perwakilan rakyat, baik dari perwakilan politik maupun dari perwakilan daerah.

Dalam penelitian yang dilakukan oleh Firman Manan (2015) tentang Dewan Perwakilan Daerah Republik Indonesia dalam Sistem Pemerintahan Republik Indonesia dijelaskan bahwa lemahnya peran DPD dikarenakan DPD tidak diberikan fungsi untuk membuat UU sebagaimana DPR. DPD paling jauh hanya ikut membahas suatu RUU dan hanya dapat mengajukan RUU yang berkaitan dengan kepentingan daerah kepada DPR. Hal ini membuat DPR menjadi lebih superior dari 
DPD, padahal kedudukan antara DPD dan DPR adalah sama dan sederajat. Perbedaan antara DPR dan DPD hanya pada fungsi dan sumber legitimasinya, di mana DPD lebih berorientasi pada kepentingan daerah (nonpolitical chambers) sedangkan DPR lebih berorientasi pada kepentingan politik yang dalam pembuatan suatu UU diwakili oleh kepentingan ideologi partai politik yang mengusung (political chambers). Hal ini dapat dibuktikan bahwa dalam periode 2004-2009 dari 19 RUU yang diajukan DPD kepada DPR, tidak satu pun yang ditindaklanjuti oleh DPR (Firman Manan, 2015).

Sejalan dengan penelitian yang dilakukan oleh Firman Manan (2015), ketidakoptimalan DPD juga dijelaskan dalam penelitian yang dilakukan oleh Abdurrachman Satrio (2015) tentang Peran Legislasi Majelis Tinggi di Indonesia dan Jerman: Perbandingan antara DPD dengan Bundesrat. Penelitian ini secara spesifik menyimpulkan bahwa perbandingan fungsi DPD dan Bundesrat dapat dikatakan berbanding terbalik. Peran DPD dalam pembuatan UU hanya sebatas pada "assistance" bagi DPR, sedangkan fungsi Bundesrat sangat luas dan kompleks bahkan dapat disebut sebagai "effective rivalry", sehingga Bundesrat dapat mengimbangi perwakilan politik dalam proses perumusan UU (Abdurrachman Satrio, 2015). Kedua penelitian sebelumnya yang dilakukan oleh Firman Manan (2015) dan Abdurrachman Satrio (2015) hanya menganalisis faktor dan penyebab ketidakoptimalan peran DPD, khususnya pada penelitian Abdurrachman Satrio (2015) yang memperbandingkan DPD dengan Bundesrat (lembaga perwakilan daerah Jerman). Penelitian yang penulis lakukan ini lebih berfokus pada upaya untuk merekonstruksi konstitusi untuk memperbaiki fungsi DPD supaya lebih optimal serta menggunakan optik perbandingan negara lain yaitu dengan negara Belanda dan Amerika Serikat, sehingga penelitian ini berbeda dengan dua penelitian sebelumnya.

Bertitik tolak dari penjelasan tersebut, maka dalam penelitian ini terdapat permasalahan hukum yang dikaji yaitu berkaitan dengan hukum yang dicita-citakan (ius constituendum) dengan hukum positif yang sedang berlaku (ius constitutum). Dalam hal ini yaitu berkaitan dengan hukum yang sedang berlaku, norma dalam konstitusi belum memadai untuk mengoptimalkan fungsi DPD dalam pembuatan UU, sehingga semangat pembentukan DPD pada amandemen ketiga UUD NRI 1945 belum optimal terfasilitasi dalam konstitusi. Oleh karena itu, perlu upaya untuk merekonstruksi konstitusi supaya fungsi DPD dapat dioptimalkan dan disejajarkan dengan DPR. Dalam penelitian ini, terdapat dua rumusan masalah yaitu: (i) Bagaimana fungsi DPD jika dibandingkan dengan fungsi lembaga perwakilan regional di negara Amerika dan Belanda? Dan (ii) Bagaimana upaya rekonstruksi konstitusi untuk mengoptimalkan fungsi DPD sebagai regional representation dalam proses perumusan UU?. Penelitian ini bertujuan untuk mengetahui perbandingan fungsi DPD dengan lembaga perwakilan sejenis di negara Amerika dan Belanda serta upaya rekonstruksi konstitusi untuk mengoptimalkan fungsi DPD sebagai regional representation dalam proses perumusan UU.

\section{B. MetodePenelitian}

Tipe penelitian yang digunakan adalah penelitian hukum normatif atau normative legal research dengan beberapa pendekatan penelitian meliputi pendekatan Perundangundangan, pendekatan konseptual, pendekatan sejarah dan pendekatan perbandingan. Penelitian hukum normatif merupakan penelitian hukum yang dipengaruhi oleh doktrin hukum murni dan positivism. Secara umum, penelitian hukum normatif sering diistilahkan dengan penelitian kepustakaan (library research), hal ini dikarenakan kecenderungan penelitian hukum normatif yang menggunakan dokumen-dokumen sebagai bahan penelitiannya (Sonata, 2008). Penelitian hukum normatif juga diartikan sebagai penelitian terhadap asas-asas hukum, sistematika hukum, taraf sinkronisasi hukum, sejarah hukum sampai dengan perbandingan hukum (Bambang Sunggono, 2011). Jenis data yang digunakan dalam penelitian hukum normatif ini adalah berupa data primer, sekunder, dan tersier. Bahan hukum primer 
yang digunakan dalam penelitian ini diantaranya: UUD NRI 1945, Putusan Mahkamah Konstitusi, Putusan Mahkamah Agung, Konstitusi AS, dan Konstitusi Belanda, serta peraturan perundang-undangan yang terkait. Bahan hukum sekunder yang memiliki kaitan dengan bahan hukum primer untuk membantu menganalisis bahan hukum primer seperti jurnal ilmiah, buku-buku yang ditulis oleh para ahli hukum, serta naskahnaskah penelitian lain yang sejenis. Sedangkan bahan hukum tersier yang membantu menjelaskan bahan hukum primer dan bahan hukum sekunder seperti kamus hukum (Black Laws Dictionary) dan lain sebagainya dan ensiklopedia. Adapun teknik pengumpulan data yang digunakan menggunakan studi kepustakaan. Dari data-data yang terkumpul kemudian dianalisis secara kualitatif-normatif dengan jalan menafsirkan dan mengkontruksikan pernyataan yang terdapat dalam dokumen dan perundang-undangan serta menggunakan pendekatan perundangundangan (statuteapproach), pendekatan analitis (analytical approch, serta pendekatan perbandingan (comparative approach).

\section{Hasil dan Pembahasan}

Gagasan dibentuknya sebuah lembaga perwakilan daerah di parlemen sebenarnya sudah ada dan dibahas di awal masa pendirian pasca proklamasi Republik Indonesia. Salah satunya dikatakan oleh Moh. Yamin dalam rapat perumusan UUD 1945 oleh BPUPKI yakni kekuasaan yang dipegang oleh permusyawaratan oleh seluruh rakyat Indonesia diduduki tidak saja oleh wakil daerah-daerah Indonesia, tetapi semata-mata pula oleh wakil golongan atau rakyat Indonesia seluruhnya (Kementerian Sekretariat Negara Republik Indonesia, 2011). Dibentuknya lembaga DPD ini sejatinya bertujuan untuk memperkuat konsep bicameralism yang ingin dilaksanakan oleh Negara Indonesia untuk memperkuat konsep "double check" serta memperkuat sistem pemerintahan presidensial.

DPD sebagai lembaga negara yang lahir dari "rahim" reformasi, dengan kata lain merupakan lembaga negara hasil konsepsi amandemen UUD 1945, sejatinya adalah sebagai bagian dari konfigurasi politik yang mendasari pada gegasverhouding (hubungan kekuasan) yang bersifat demokratis yang berdampak pada produk hukum yang responsive (Moh. Mahfud MD, 2014). Beranjak dari sini, maka sejatinya pendirian lembaga DPD memang dikonsepsikan untuk mengidealkan fungsi legislasi supaya tidak hanya diwakili oleh DPR yang hanya berorientasi pada political representation sekaligus juga menjamin adanya regional representation untuk mewadahi adanya konsepsi otonomi daerah (J.J. Rousseau, 1986). Selain itu, terbentuknya DPD juga sebagai respon atas adanya tuntutan reformasi pada tahun 1998 yaitu: (i) Penegakan supremasi hukum, (ii) Pemberantasan KKN. Reformasi birokrasi sebagai syarat pemberantasan KKN, (iii) Mengadili mantan Presiden Soeharto dan krooni-kroninya, (iv) amandemen konstitusi, (v) Pencabutan doktrin dwifungsi ABRI (TNI/POLRI), (vi) Pemberian otonomi daerah yang seluas-luasnya(Yongki Gigih Prasisko, 2016). Khususnya, terkait dengan tujuan reformasi nomor (vi) yaitu pemberian otonomi daerah yang seluasluasnya dimaksudkan supaya dalam melakukan berbagai tindakan yang diharapkan akan sesuai dengan kondisi serta aspirasi masyarakat di sekitarnya. Konsensus politik Bangsa Indonesia melalui Reformasi Tahun 1998 telah menghasilkan tata pemerintahan Negara Republik Indonesia yang dituangkan dalam amandemen UUD 1945 (I Putu Hendra Wijaya, 2014). Akhirnya anggapan tersebut disebabkan karena secara logis pemerintah daerah lebih dekat kepada masyarakat, sehingga akan lebih tahu apa yang menjadi tuntutan dan keinginan masyarakat (Sakinah Nadir, 2013). Pemberian otonomi daerah yang seluas-luasnya inilah yang kemudian membutuhkan adanya suatu badan representasi/perwakilan rakyat yang dapat menyalurkan aspirasi rakyat di daerah serta dapat mengefektifkan dan mengefisiensi otonomi daerah dalam pembuatan undangundang atau kebijakan-kebijakan dari pemerintah pusat yang berdampak pada masyarakat di daerah. 
Secara historis, gagasan mengenai adanya DPD terjadi pada amandemen ketiga yaitu pada tahun 2001, di mana lahirnya DPD selain sebagai upaya untuk memperjuangkan kepentingan daerah di tingkat parlemen juga sebagai lembaga tersendiri yang lebih menyerupai "utusan daerah" di MPR sebelum amandemen UUD NRI 1945 dengan memberikan porsi yang lebih ideal terkait fungsi legislasinya (Tim Penyusun Naskah Komprehensif Perubahan Undang-Undang Dasar Republik Indonesia, 2010). Akan tetapi, hal ini justru berbanding terbalik dengan pengaturan DPD di dalam UUD NRI 1945 ternyata masih sangat sumir. DPD sama sekali tidak mempunyai kekuasaan apa pun karena hanya memberikan masukan pertimbangan, usul ataupun saran, sedangkan yang berhak memutuskannya adalah DPR. Karena itu, keberadaan DPD di samping DPR tidak menunjukkan kedudukan kedua kamar di legislatif sama kuat atau dengan kata lain, DPD hanya memberi masukan, sedangkan yang memutuskan adalah DPR sehingga DPD ini lebih tepat disebut sebagai Dewan Pertimbangan DPR karena kedudukannya hanya memberikan pertimbangan kepada DPR (Ni'matul Huda, 2016).

Apabila diperhatikan fungsi, tugas, dan wewenang yang dimiliki DPD cenderung sebagai lembaga pertimbangan DPR. Oleh karena itu, dalam penelitian ini diberikan perbandingan peran DPD dengan peran lembaga negara di negara lain yang memiliki kedudukan dan fungsi seperti DPD di Indonesia dengan dua negara pembanding yaitu Amerika Serikat dan Belanda(Jimly Asshidiqie, 2006a). Alasan menggunakan pembanding dari kedua Negara yaitu Amerika Serikat dan Belanda dilandasi oleh dua alasan pokok yaitu: pertama, berdasarkan dari bentuk dan sistem pemerintahan di Indonesia Negara Amerika Serikat memiliki kesamaan dengan Indonesia yaitu sama-sama memiliki bentuk pemerintahan republik dan sama-sama memiliki sistem pemerintahan presidensial, yang membedakan hanyalah bentuk negaranya saja yaitu kalau Indonesia bentuk negaranya adalah kesatuan sedangkan Amerika Serikat adalah Negara federal. Hal itu juga dapat dipahami bahwa Amerika Serikat merupakan the mother of presidential system sekaligus merepresentasikan negara dengan sistem hukum common law. Oleh karena itu, mengutip apa yang disampaikan oleh Douglas V. Verney bahwa sebaiknya terlebih dahulu menelaah sistem politik Amerika Serikat, jika hendak memulai kajian tentang sistem presidensial (Andy Wiyanto, 2015). Kedua, terkait dengan Belanda hal ini dilandasi bahwa Belanda memiliki hubungan historis dengan Indonesia dikarenakan Indonesia merupakan koloni dari Pemerintah Hindia Belanda (Dutch East Indie). Dampak dari adanya penjajahan Belanda atas Indonesia dalam kepustakaan hukum menghasilkan suatu asas konkordansi (Domiri, 2016). Dampak dari adanya asas konkordansi ini adalah membuat beberapa peraturan-peraturan yang diterapkan oleh Pemerintah Kolonial Belanda juga dilaksanakan oleh Indonesia setelah merdeka, hal ini dapat dibuktikan dengan adanya kodifikasi beberapa undang-undang diantaranya: KUHP, KUHPer, dan KUHD. Terlebih lagi, dampak dari adanya asas konkordansi adalah bahwa hukum nasional Indonesia lebih bercorak pada hukum kontinental yang mengutamakan bentuk sistem hukum tertulis (geschvenrecht-written law) (Zainal Arifin Hoesein, 2012). Hal ini juga semakin mempertegas bahwa sistem hukum common law dan civil law yang mayoritas dianut oleh Negara-negara di dunia, sehingga perbandingan fungsi DPD di Indonesia dengan fungsi lembaga perwakilan daerah di Negara lain juga sebagai representasi dari dua sistem hukum terbesar di dunia.

Amerika Serikat menganut fungsi legislasi dipegang oleh dua kamar yaitu senate dan house of representative dengan struktur parlemen yang bersifat bicameral di mana kedua kekuasaan memiliki kekuasaan yang berimbang satu dengan yang lainnya (strong bicameralism). Sehingga setiap undangundang harus memenuhi kedua kamar tersebut (Sofyan Hadi, 2013). Senate di Amerika Serikat pada awalnya dpilih oleh Badan Legislatif Daerah atau yang di Indonesia dikenal dengan istilah Dewan Perwakilan Rakyat Daerah. Namun pada tahun 1913 
setelah amandemen ketujuh belas para senator dipilih langsung oleh rakyat melalui pemilihan umum(R. Guntur Prakoso Dewandaru, 2016). Berdasarkan US Constitutionamandement XXVII 1992 bahwa mengenai struktur dan susunan senat terdapat dalam Article 1 ayat (3) yang berbunyi "The Senate of the United States shall be composed of two Senators from each State (chosen by the Legislature thereof)......". Kemudian terkait dengan tugas dan wewenang dari senate terdapat dalam Article 1 ayat (7) yakni "All bills for raising Revenue shall originate in the House of Representatives; but the Senate may propose or concur with Amendments as on other Bills. Every Bill which shall have passed the House of Representatives and the Senate, shall, before it become a Law, be presented to the President of the United States.....", di mana dalam hal ini senat juga diperbolehkan untuk menyetujui maupun mengusulkan perubahan suatu RUU. Selain itu, senate bersama dengan House of Represntative juga mempunyai kekuasaan yang cukup besar dalam mengajukan suatu RUU kepada Presiden.

Hal yang menjadi titik tekan di sini bahwa kedudukan senate cukup kuat dikarenakan memiliki kewenangan yang sejajar dengan House of Represntative baik ketika mengajukan RUU maupun ketika RUU di veto oleh presiden. Sehingga, di Amerika Serikat pembentukan undang-undang melibatkan tiga institusi sekaligus yaitu DPR (House of Representative), Senat, dan Presiden. Praktik di Amerika Serikat juga menunjukkan bahwa RUU yang akan diajukan oleh pemerintah kepada kongres pada umumnya dipersiapkan oleh departemen-departemen yang dipimpin oleh presiden(Aminuddin Kasim, 2011).Hal yang sangat kontras ketika dibandingkan dengan kewenangan DPD yang hanya dapat mengajukan RUU kepada DPR, ikut membahas, dan ikut mengawasi pelaksanaan undang-undang yang berkaitan dengan kepentingan daerah. Sehingga, DPD tidak lebih hanya sebagai pemberi usul dan saran bagi DPR bahkan dalam istilah hukum dikenal sebagai "co-legislator" bagi DPR.

Negeri Kincir Angin Belanda melembagakan parlemen yang disebut "the states general" terdiri atas dua kamar yaitu Eeerste Kamer (Majelis Tinggi) serta dan The Tweede Kamer (Majelis Rendah) di mana peran Eeerste Kamer sebagai regional representative memiliki kesamaan dengan DPD di Indonesia seperti masing-masing dipilih melalui daerah/provinsi dan para anggota juga mewakili daerah/provinsi mereka masing-masing(Putri Noor Ilham dan Deny Prihatmadja, 2008). Di Belanda kapasitas kedua parlemen relatif sebanding yang terdiri dari kamar pertama (Eerste kamer) dan kamar kedua (Tweede kamer). Anggota kedua kamar dipilih dengan cara perwakilan proporsional terbatas untuk jangka waktu 4 tahun. Peran Eerste kamer lebih banyak saat jointsession dan dalam proses legislasi kamar ini yang akan memutuskan RUU yang dikirim oleh Tweede kamer (Fajlurrahman Jurdi, 2016).Oleh karenanya, dalam bidang legislasi kedudukan Eeerste Kamer dan Tweede Kamer adalah sama dan sejajar. Anggota dari kedua majelis ini dapat mengajukan RUU atau UU (Tim CEPP UI, 2015). Selain itu, anggota Eeerste Kamer dan Tweede Kamer juga dapat mengajukan pertanyaan tertulis kepada pemerintah. Jika dibandingkan dengan fungsi dan kewenangan DPD di Indonesia, maka sistem keorganisasian pada Eeerste Kamer hanya mirip substansi pada hal keterwakilan dari anggota-anggotanya, di mana anggota pada kedua lembaga parlemen ini sama-sama mewakili masing-masing provinsi atau daerah yang memilihnya. Namun jika menilik wewenang DPD sebagaimana yang tercantum dalam pasal 22D UUD NRI 1945, maka DPD tidak memiliki kewenangan yang berarti di MPR. Hal tersebut sangat kontras jika dibandingkan dengan kewenangan dariEeerste Kamer yang memang sama-sama memiliki kewenangan yang sederajat denganTweede Kamer. Diantara kewenangannya yaitu: mengesahkan dan memutuskan suatu RUU menjadi UU, menerima atau menolak RUU yang diajukan oleh Perdana Menteri atau Dewan Kabinet, mengangkat dan memberhentikan Perdana Menteri, dan mengangkat dan memberhentikan Ketua Mahkamah Agung serta Hakim Agung. Sehingga dapat disimpulkan dari perbandingan 
dengan Negara Amerika Serikat dan Belanda maka peran DPD di Indonesia masih sangat terbatas dan belum mampu menjadi kamar yang mengoptimalkan fungsi legislasi untuk setara dan sederajat dengan DPR.

Sejalan dengan perbandingan lembaga perwakilan daerah di Negara Belanda dan Amerika Serikat maka penguatan fungsi DPD perlu untuk diwujudkan. Hal ini berdasarkan pada teori organ di mana organ kekuasaan negara dibagi menjadi dua yaitu: state main organ dan state auxiliary organ. State main organ merupakan lembaga utama negara. Dalam sistem ketatanegaraan Indonesia yang termasuk state main organdiantaranya: (i) Presiden,(ii) DPR, (iii) DPD, (iv) MPR, (v) MK, (vi) MA, (vii) BPK. Lembaga tersebut dapat disebut sebagai lembaga tinggi negara. Yang dapat disebut sebagai lembaga tinggi negara yang utama tetaplah lembaga-lembaga tinggi negara yang mencerminkan cabang kekuasaan utama negara, yaitu legislative, executive, dan judicial(Janedri M. Gaffar, 20019). Selain state main organjuga dibentuk lembaga-lembaga pembantu (state auxiliary organ) yang mempunyai fungsi melayani(Ahmad Basarah, 2014). Perbedaan diantara state main organ dan state auxiliary organ dapat dibedakan dalam tiga ranah (domain), yaitu: (i) kekuasaan eksekutif atau fungsi pemerintahan, (ii) kekuasaan legislatif dan fungsi pengawasan, dan (iii) kekuasaan kehakiman atau fungsi yudisial. Dalam hal ini, kedudukan DPD sebagai state main organ perlu diperjelas dan difungsikan sebagai mana mestinya agar tidak menjadi seperti "state auxiliary organ" bagi DPR. Sehingga, penguatan DPD juga sebagai upaya untuk memelihara a careful check on the sometimes hasty decisions of a first chamber serta untuk memelihara prinsip double check yang memungkinkan setiap produk legislatif diperiksa dua kali sehingga terjamin kualitasnya sesuai dengan aspirasi rakyat. Hal ini untuk mempertegas bahwa kedua kamar (dalam hal ini DPR dan DPD) benar-benar mewakili aspirasi rakyat yang berbeda satu sama lain sehingga mencerminkan gabungan kepentingan rakyat (Ni'matul Huda, 2008). Oleh karena itu, beberapa upaya rekonstruksi konstitusi yang ditawarkan diantaraya (i) Mengamandemen Pasal 20 UUD NRI 1945, di mana kekuasaan membentuk UU tidak boleh dimonopoli oleh DPR saja, melainkan juga harus ada peran DPR di dalamnya (ii) Mengamandemen Pasal 22D UUD NRI 1945 tentang mekanisme pengajuan RUU dari DPD ke DPR, hal ini perlu dipertegas dan adanya pembagian tugas antara DPR dan DPD dalam pembuatan UU, sehingga pembentukan UU dilakukan secara tripartite yaitu antara: DPR, DPD, dan Presiden (iii)perubahan UU MD3, UU Pembentukan Peraturan PerundangUndangan, serta Peraturan Tata Tertib DPD, serta penegasan bahwa dalam pemilihan DPD dilakukan oleh calon perseorangan (bukan anggota partai politik) untuk menegaskan kedudukannya sebagai regional representation.

\section{Simpulan}

Belum optimalnya fungsi DPD dalam pementukan UU merupakan implikasi dari atrubusi dalam konstitusi yang masih terkesan sumir memberikan kedudukan kepada DPD. DPD masih dipandang sebagai co-legislator yang fungsinya hanya sebagai assistance bagi DPR dalam pembuatan UU. Jika dibandingkan dengan negara lain, dalam hal ini Amerika Serikat dan Belanda, fungsi DPD dikatakan masih belum optimal dan oleh karena itu diperlukan pembaharuan fungsi DPD supaya dapat optimal dalam menjalankan fungsinya. Hal ini mengindikasikan perlunya persamaan kedudukan antara DPR dan DPD serta pembagian tugas yang jelas dalam proses penyusunan UU.

Sejalan dengan hal tersebut, maka rekonstruksi konstitusi perlu untuk dicanangkan dengan beberapa tahap diantaranya mengamandemen Pasal 20 dan 22D UUD NRI 1945 serta merevisi beberapa undang-undang seperti UU MD3, UU Pembentukan Peraturan Perundang-Undangan, Peraturan Tata Tertib DPD dengan mempertegas pemilihan anggota DPD haruslah dilakukan dengan pemilihan perseorangan (bukan melibatkan partai politik). 


\section{DAFTAR PUSTAKA}

Abdurrachman Satrio. (2015). Fungsi Majelis Tinggi di Indonesia dan Jerman: Perbandingan antara DPD dan Bundesrat. Jurnal RechtsVinding, 4(3), 385.

Ahmad Basarah. (2014). Kajian Teoritis Terhadap Auxiliary State Organ dalam Struktur Ketatanegaraan Indonesia. Jurnal Masalah-Masalah Hukum, 43(1), 2.

Aminuddin Kasim. (2011). Proses Pembentukan Undang-Undang Pasca Pergeseran Kekuasaan Legislatif dari Presiden ke DPR. Jurnal Akualita, 6(3), 5.

Andy Wiyanto. (2015). Kekuasaan Membentuk Undang-Undang dalam Sistem Pemerintahan Presidensial Setelah Perubahan Undang-Undang Dasar 1945. Jurnal Negara Hukum, 6(2), 138.

Bambang Sunggono. (2011). Metodologi Penelitian Hukum. Jakarta: PT. Rajagrafindo Persada.

Domiri. (2016). Tinjauan Filosofis dan Teoritis Penggunaan Hukum Acara HIR/RBG dalam Penyelesaian Sengketa Waris di Pengadilan Agama. Jurnal Hukum Dan Pembangunan, 46(2), 225.

Fajlurrahman Jurdi. (2016). Eksistensi Parlemen Indonesia Setelah Amandemen Konstitusi. Jurnal Staatrecht, 1(2), 6.

Firman Manan. (2015). Dewan Perwakilan Daerah Republik Indonesia dalam Sistem Pemerintahan Republik Indonesia. Jurnal Ilmu Pemerintahan, 1(1), 49.

I Putu Hendra Wijaya, dkk. (2014). Fungsi Legislasi DPD-RI Berdasarkan Pasal 22D Undang-Undang Dasar Negara Republik Indonesia Tahun 1945. Jurnal Kertha Semaya, 3(2), 3.

J.J. Rousseau. (1986). Kontrak Sosial (Terjemahan). Jakarta: Erlangga.

James R. Rodgers. (n.d.). The Advantage of Second Chambers in Republican Legislature: An Informational Theory. Texas A\&M University: Department of Political Science.

Janedri M. Gaffar. (20019). Konsolidasi Lembaga Negara Pasca Perubahan UUD
1945.

Jimly Asshidiqie. (2006a). Model-Model Pengujian Konstitusional di Berbagai Negara. Jakarta: Sinar Grafika.

Jimly Asshidiqie. (2006b). Pengantar Hukum Tata Negara Jilid I. Jakarta: Sekretariat Jenderal dan Kepaniteraan Mahkamah Konstitusi RI.

Jimly Asshidiqie. (2006c). Pengantar Hukum Tata Negara Jilid II. Jakarta: Sekretariat Jenderal dan Kepaniteraan Mahkamah Konstitusi RI.

Kementerian Sekretariat Negara Republik Indonesia. (2011). , Profil Lembaga Negara Rumpun Legislatif. Jakarta: Asisten Deputi Hubungan Lembaga Negara dan Lembaga Non StrukturalDeputi Bidang Hubungan Kelembagaan dan Kemasyarakatan Kementerian Sekretariat Negara.

Mariana Llanos dan Detlef Nolte. (2003). Bicameralism in The Americas: Around The Extremes of Symmetry and Incongruence. The Journal of Legislative Sudies, 9(3), 71.

Miki Pirmansyah. (2014). Eksistensi Dewan Perwakilan Daerah Dalam Sistem Bikameral Di Indonesia. Jurnal Cita Hukum, 1(1), 2.

Moh. Mahfud MD. (2014). Politik Hukum di Indonesia. Jakarta: Rajawali Pers.

Ni'matul Huda. (2008). Gagasan Amandemen (Ulang) UUD 1945 (Usulan untuk Penguatan DPD dan Kekuasaan Kehakiman). Jurnal Hukum Ius Quia Iustum, 15(3), 382.

Ni'matul Huda. (2016). Hukum Tata Negara Indonesia. Jakarta: PT. Rajagrafindo Persada.

Prayudi. (2006). DPD dan Sistem Bikameral. Jurnal Ketahanan Nasional, 11(3), 42.

Putri Noor Ilham dan Deny Prihatmadja. (2008). Kedudukan Dewan Perwakilan Daerah dalam Sistem Ketatanegaraan Indonesia. Jurnal Lex Jurnalica, 5(2), 73.

R. Guntur Prakoso Dewandaru. (2016). Perbandingan Badan Perwakilan Rakyat Pada Sistem Ketatanegaraan Indonesia dan Amerika Serikat. Diponegoro Law Journal, 5(3), 10. 
Sakinah Nadir. (2013). Otonomi Daerah dan Desentralisasi Desa: Menuju Pemberdayaan Masyarakat Desa. Jurnal Politik Profetik, 1(11), 3.

Sofyan Hadi. (2013). Fungsi Legislasi dalam Sistem Pemerintahan Presidensial. Jurnal Ilmu Hukum, 9(18), 82.

Sonata, D. L. (2008). Metode Penelitian Hukum Normatif dan Empiris: Karakteristik Khas dari Metode Meneliti Hukum. Jurnal Justicia, 8(1), 24.

Tim CEPP UI. (2015). Mengenal Lebih Dekat Parlemen Belanda. Parlementaria, 74.
Tim Penyusun Naskah Komprehensif Perubahan Undang-Undang Dasar Republik Indonesia. (2010). Naskah Komprehensif Perubahan Undang Undang Dasar Negara Republik Indonesia Tahun 1945 Buku III. Jakarta: Sekretariat Jenderal dan Kepaniteraan Mahkamah Konstitusi RI.

Yongki Gigih Prasisko. (2016). Gerakan Sosial Baru di Indonesia: Reformasi 1998 dan Proses Demokratisasi di Indonesia. Jurnal Pemikiran Sosiologi, 3(2), 13.

Zainal Arifin Hoesein. (2012). Pembentukan Hukum dalam Perspektif Pembaruan Hukum. Jurnal RechtsVinding, 1(3), 315. 